\title{
Progress in innovation and knowledge management research: from incremental to
} transformative innovation

\author{
Nuttaneeya (Ann) Torugsa, University of Tasmania \\ Wayne O’Donohue, Griffith University
}

August 2015

The authors thank Arch Woodside, Boston College, for his comments and encouragement during the preparation of this article. Send correspondence to Nuttaneeya (Ann) Torugsa, Australian Innovation Research Centre, University of Tasmania, Private Bag 108, Hobart, Tasmania 7001, Australia (email: Nuttaneeya.Torugsa@utas.edu.au); Wayne O’Donohue, Department of Employment Relations and Human Resources, Griffith University, Gold Coast campus, Queensland 4222, Australia (email: w.odonohue@griffith.edu.au). 


\begin{abstract}
This study assesses progress in innovation and knowledge management research during 1980-2014, using a sample of "highly-cited” journal publications. The assessment reveals a transformation in research from incremental to transformative innovation. The study discusses the nature of this transformation and outlines a future research agenda for the development of better research design and new competencies in theory and practice.
\end{abstract}

Keywords: Transformative innovation; theory; method; complexity. 


\section{Introduction}

This study assesses progress in the innovation and knowledge management (KM) literature in the 1980-2014 period - from incremental to transformative innovation in research - through a discussion and synthesis of key "highly-cited” journal articles in the ISI Web of Knowledge Social Sciences Citation Index (SSCI). The study adopts the view that transformative innovation in research is distinct from incremental innovation in its contribution to prevailing knowledge. Specifically, whilst incremental innovation (i.e., minor improvements) reinforces prevailing knowledge or refines existing theories, transformative innovation (i.e., radical initiatives that account for context sensitivity, multiple realities and the synergy between theory, method, analysis and practice) redirects prevailing knowledge and provides major advances in developing better theories.

This study acknowledges the importance of both types of innovation in research; however, transformative innovation is the focus due to its potential to move research forward. Such an innovation is particularly relevant to the field of innovation-KM where the highly complex, context-specific, and intrinsically paradoxical nature of innovation-KM processes requires researchers to incorporate context into a research design and apply methods that accurately capture the paradoxical character of such processes. The purpose of this study is to stimulate consideration of this transformation in innovation-KM research as the basis for an interesting and impactful future research agenda, leading to the development of better research design and the advancement of theories that bridge the scholar-practitioner divide.

\section{Method}

The process of selecting the sample of key articles for review consisted of five steps. Step 1 involved a search of all articles available in the SSCI database using broad criteria, including: keywords “innovation” and "knowledge management”; timespan “1980-2014”; 
research domains "social sciences” or "science technology”; domain type “article”; research area "business economics"; and language “English”. These criteria produced an initial selection of 7,768 articles.

As the number of citations an article achieves serves as a de facto vote on the quality of an article's contribution to knowledge accumulation (Podsakoff, MacKenzie, Bacharach, \& Podsakoff, 2005), Step 2 applied a selection criterion of more than five citations per year on average (Crossan \& Apaydin, 2010). This process resulted in the reduction of the initial selection of articles to 363 "highly-cited” articles. Recognizing citation biases arising from the time lag between publication and citation, Step 3 varied the selection criterion for identifying highly-cited articles. Specifically, the minimum number of citations per year was reduced from five to two for articles published in 2012-2014; and an additional criterion that publication occurred in a top journal - was incorporated. This additional criterion reflects the premise that top journals - defined as the top 80 business and management journals listed in Thomson’s Journal Citation Social Sciences Edition Report 2013 - are more likely to publish articles that achieve high citation numbers. The application of these modified selection criteria added an additional 57 articles to give a total of 420 highly-cited articles.

In Step 4, all 420 article abstracts were read with 204 articles being eliminated on the basis that innovation-KM was not their main content focus. This process produced a reduced selection of 216 highly-cited articles.

To achieve parsimony and facilitate interpretation of progress in innovation-KM research, Step 5 entailed selecting a sample of “transformative” articles (Table 1) from the 216 highly-cited articles. These articles were selected on the basis that they challenged established innovation-KM tenets, abandoned methodological rigidity, and focused on achieving synergies between theory, method, analysis and practice. Specifically, each of the transformative articles redirected prevailing knowledge by considering the causal-complex 
and context-specific conditions under which the processes of innovation-KM operate, and used alternative theories and methods to explain those processes realistically.

To mitigate the subjectivity inherent in the classification of transformative articles and provide an objective point of reference for assessment of research progress, a group of 12 “highest-cited” articles (Table 1) was also identified in the selection of 216 highly-cited articles. Five of the 12 highest-cited articles overlapped with the transformative group, while the research contributions of the remaining seven highest-cited articles were nontransformative and incremental (i.e., each reinforced/refined prevailing knowledge).

The next section provides an overview by grouping of the 19 key articles included in this assessment of progress in innovation-KM research, 1980-2014.

Table 1 here.

\section{Overview of selected articles}

\subsection{Highest-cited incremental articles}

The seven articles in the "highest-cited incremental” group present novel ideas that have largest impacts in terms of reinforcing prevailing knowledge. These articles refine existing theories by focusing more on the outcomes of innovation-KM processes (instead of the processes themselves), and/or by using symmetric-net-effects analytic methods (e.g., multivariate regression) to build or test theory; methods which do not match well with the dynamic and causally complex nature of innovation-KM processes.

The high number of citations achieved by Cohen and Levinthal (1990) testifies to the article's influential redefinition of the concept of absorptive capacity. Using data on firm investment in research and development $(R \& D)$, the article redefines absorptive capacity as the firm's ability to recognize value, assimilate and apply new external knowledge for innovation. Building on Cohen and Levinthal's work, Lane and Lubatkin (1998) use data on 
R\&D alliances to develop a modified construct of relative absorptive capacity. These two empirical articles, while recognizing the dynamism and non-linearity of absorptive capacity in theoretical arguments, use symmetric (linear) regression to model their data and test theory.

Levinthal and March (1993) examine the constraints on organizational learning and identify three forms of "learning myopia": overlooking the need to take long-term issues into account by addressing short-term issues only; focusing only on the details and ignoring the larger picture; and, over-emphasizing learning successes and de-emphasizing failures.

Szulanski (1996) examines the internal stickiness of knowledge transfer and tests a model using correlation analysis of best-practice transfers. This article is unique in its novel findings showing knowledge-related factors as impediments to a firm's ability to transfer knowledge internally and to acquire the benefits from innovation.

Teece (1998) considers KM from a perspective that incorporates a more traditional view of dynamic capabilities, with the high citation count reflecting a shift in focus from cost minimization to value maximization. Hansen et al. (1999) reveal the use of two different types of KM strategies in consulting firms: codification and personalization, and go on to demonstrate how managers can explicitly connect their firm's innovation-based competitive strategy to the way they use knowledge to support it. In the final article in this group, Subramaniam and Youndt (2005) use moderated regression analysis to model and test longitudinal data. Their results extend understanding of the KM-innovation link by revealing how different aspects of intellectual capital influence innovative capabilities.

\subsection{Highest-cited transformative articles}

Using a complementarity approach to theory construction/reconceptualization, the five articles in the "highest-cited transformative” group display at least one of three defining characteristics: namely, (i) a focus on the contexts and mechanismic processes of innovation- 
KM; (ii) a linkage of the individual- and organizational-level in research design; and (iii) a recognition that one attribute/factor can have different effects (positive/negative) depending on the context in which it operates.

Nonaka (1994) presents a dynamic theory of organizational knowledge creation and posits that $\mathrm{KM}$ is crucial in providing the organization with the ability to create/exploit new knowledge continuously in a recursive process that underpins organizational innovation. The use of a model of dynamic interaction between tacit and explicit knowledge provides a multilevel perspective on how individual-level knowledge can be amplified and influence knowledge creation at the organizational level. Grounded in hands-on research and practice, Nonaka’s theory conceptualizes KM for organizational innovation as a mechanismic process that involves a complex and dynamic pattern of factors within and outside the organization.

Grant (1996) articulates the theoretical foundations for a knowledge-based view in which the firm's primary KM objective is the integration/application of the wide array of specialized knowledge that resides in individuals, with management's primary task being the establishment of the necessary coordination mechanisms for knowledge integration. The article presents two transformative ideas, namely that: knowledge as a resource is subject to uniquely complex and unpredictable problems of appropriability; and, multiple mechanisms for coordination lead to complexity and causal ambiguity in knowledge integration processes.

Eisenhardt and Martin (2000) make a transformative research contribution with their explanation of the nature of dynamic capabilities (e.g., innovation) which they present as specific strategic and organizational processes, guided by learning mechanisms, which enable firms to manipulate resources into new value-creating strategies within dynamic markets. They argue that dynamic capabilities are necessary but not sufficient conditions for competitive advantage, the value of which resides not in the capabilities themselves but in the resource configurations that such capabilities enable firms to create. 
Zahara and George (2002) adopt a pragmatic novel approach to redevelop the concept of absorptive capacity as a dynamic, multidimensional capability that shapes the nature of a firm's knowledge creation and innovation. The transformative research contribution of this article is evident in its: incorporation of the notions of complexity, uncertainty and nonlinearity; emphasis on dynamic (potential/realized) capabilities geared toward transformative change; and, focus on multiple exogenous and endogenous contingencies as well as broader managerial roles as key influential factors in organizational knowledge and innovation.

Carlile (2002) presents a pragmatic but radical view of "knowledge-in-practice”, in which knowledge is "localized, embedded, and invested within a function and how, when working across functions, consequences often arise that generate problematic knowledge boundaries” (p.442). This article provides a mechanismic explanation of why knowledge is both a barrier and a source of innovation (the opposite effects of knowledge on innovation).

\subsection{Non-highest-cited transformative articles}

The seven transformative articles not in the "highest-cited” group explicitly apply complexity science to innovation-KM research, and/or present rigorous analysis in terms of real-life situations and multiple realities, using alternative set-theoretic methods grounded in complexity science and the assumption of asymmetry between multiple attributes.

The article by Choi et al. (2008) contributes significantly to innovation-KM research through adoption of a complementarity approach that supports elaborate explanations of complex processes, for examining the relationships among KM strategies and their impacts on organizational performance and innovativeness. Using association analysis algorithms, the findings reveal three types of KM strategy relationships (non-complementarity, non-critical symmetric complementarity, and asymmetric complementarity), and a complementarity 
between "tacit-internal-oriented” and “explicit-external-oriented” KM strategies with synergistic effects on performance.

Drawing on complexity science, Uhl-Bien et al. (2007) develop a framework for the study of complexity leadership theory - a leadership paradigm that emphasizes a complex interplay among heterogeneous agents and focuses on enabling the learning, innovative and adaptive capacity of “complex adaptive systems” (CAS) within the specific context of knowledge-producing organizations. The article redirects innovation-KM research toward mechanisms and contexts (and away from variables), and the utilization of an agent-based modeling (ABM) methodology - a by-product of explorations into CAS that measures specific characteristics and interactions of a social group, and permits researchers to experiment with "what-if” scenarios.

Garcia (2005) also urges scholars to employ the simulation technique ABM in research on innovation and new product development in order to enable more realistic testing of realworld phenomena. The article identifies the strengths and weaknesses of modeling dynamic systems using $\mathrm{ABM}$, and outlines three potential areas of research where ABM has value: diffusion of innovations, organizational strategy, and knowledge/information flows.

Siggelkow and Rivkin (2006) report on the use of ABM in a multi-level organizational context to examine how micro/individual-level factors impact at the macro/organizationallevel in regard to knowledge/information exchanges and cross-level interactions. This article provides evidence of a potential unintended consequence associated with greater knowledgeprocessing capacity, and highlights the merits of $\mathrm{ABM}$ as a rigorous analysis tool for forming/testing hypotheses that cross levels.

Recognizing the existence of multiple causality, where the trade-off effects of an attribute depend on the operating context (relationship with other attributes), the final three "survey-based” articles in this group redirect innovation-KM research toward using fuzzy-set 
qualitative comparative analysis (fsQCA) to estimate the alternative complex antecedent configurations (or causal recipes) that lead to a given outcome condition. Firstly, Ganter and Hecker (2014) apply fsQCA to large-scale data and reveal several equifinal configurations of firm-level attributes that have a causal asymmetric effect on the adoption of organizational innovation (i.e., new methods in KM). Next, Leischnig et al. (2014) apply fsQCA to the analysis of the complex causal patterns from alliance management capacity through interorganizational interaction quality to technology transfer success, and find multiple causal path explanations for success in technological knowledge transfer.

Finally, Ordanini et al. (2014) use fsQCA to capture the complexity of new service assessments and measure the impact of innovativeness on new service adoption. The findings reveal complex trade-off effects among individual service attributes, with only specific combinations of attributes acting as sufficient conditions for new service adoption. This article also presents comparisons, between the results from fsQCA and those from symmetric regression techniques, to show how fsQCA provides a better sense of the data in research contexts involving attribute configurations.

\section{What leads to the transformation and redirection of innovation-KM research?}

\subsection{Sense-making in theorizing complexity}

The creation and management of knowledge for successful innovation can be seen as the "fuzzy front-end" (Patokorpi \& Ahvenainen, 2009). The fuzziness occurs as a result of KM that is often unstructured, disorderly, and characterized by a series of feedback loops and overlap between various stages of implementation (Gopalakrishnan \& Damapour, 1994). The simultaneous occurrence of multiple development paths, cumulative overlap in the sequence of activities, and the conjunctive influence of activities, obscure the dynamic nature of the processes that lead to successful innovation. Consequently, non-linear processes, context- 
sensitivity and uncertainty mean that KM for innovation operates at the edge of chaos, and requires algorithmic thinking that challenges traditional ways of theorizing innovation-KM systems.

These difficulties, which make the task of sense-making in theorizing complexity quite problematic, raise doubts about the validity of the routine assumption of one "right" theory and the use of symmetric theories to explain fully and accurately innovation-KM mechanisms characterized by complex trade-off effects and several factor configurations. The weaknesses in such an approach point to the need for asymmetric thinking and the use in blended form of a variety of theories, paradigms and ideas - also known as “complexity theory” (Burnes, 2005) - to deal with the dynamism of innovation-KM phenomena, and to gain a pragmatic understanding of what is required in specific contexts to manage knowledge-based innovation successfully.

\subsection{Usability of research results in practice}

Three core criticisms of incremental research design are: failure to collect the necessary detail for gaining deep understanding of the mechanics embedded in the processes examined (Woodside, 2014); the assumed homogenization in knowledge dynamics that glosses over varieties of situated practice with different outcomes (Garcia, 2005); and overemphasis by traditional management theories on the macro-level of organizations, while micro-level theorizing (activity by individual members) is overlooked (Johnson, Melin, \& Whittington, 2003).

These criticisms raise questions about the usability/applicability of research findings to practice in innovation-KM research (Carlile, 2002), and at the same time point to the need for the adoption of a "theories-in-use" approach which provides a multi-level perspective that links organizational- with individual-level factors (Siggelkow \& Rivkin, 2006). Recognizing 
that inputs from individuals and organizations working together are a necessary antecedent to effective KM processes for successful innovation (Nonaka, 1994), the integration of microand macro-level variables in research design is essential for achieving a practical and realistic understanding of the fundamental mechanisms and configurations of factors that interact collectively to shape knowledge-based innovation outcomes.

\subsection{Pragmatism in data analysis}

Most empirical studies in innovation-KM research rely on non-experimental research designs, where researchers are unable to control/manipulate subjects but instead rely on interpretation to derive conclusions. Whilst there is general agreement in the literature about the dynamic, non-linear nature of innovation-KM systems, researchers often fail to consider these system characteristics when analyzing non-experimental data, and use "net effects" symmetric methods to model data even though patterns of relationships in the data are asymmetric (Woodside, 2014).

The focus of net effects estimation is problematic in three aspects. First, as noted by Armstrong (2012), adding many variables into an equation in non-experimental studies does not mean controlling for their effects, given the possible problems of multicollinearity among variables. Second, net effects methods cannot reflect all aspects of reality because not all cases support an exclusive negative or positive relationship between independent and outcome variables (Woodside, 2014). Lastly, the linear assumption that high/low values of an independent variable are necessary and sufficient conditions for high/low values of an outcome variable ignores the reality that several sufficient conditions may co-exist for a given outcome (Ragin, 2008; Woodside, 2013). 
The above limitations make the current symmetric dominant design logic in innovationKM research less informative and less useful theoretically and practically; and point toward the alternative logic of asymmetric testing to produce a more nuanced coverage of reality.

\section{Future research agenda for innovation-KM research}

Drawing on the research-related challenges discussed above, there are a number of promising opportunities for developing a pragmatic, holistic and impactful agenda which aims at transforming prevailing knowledge in innovation-KM research and helping bridge the theory-practice divide.

\subsection{Embracing complexity theory and abductive reasoning as a basis for theorizing}

As discussed earlier, the adoption of a single theoretical perspective can limit the extent to which researchers are able to capture the “fuzzy front-end” of innovation-KM systems. Two promising ways for fully revealing the inner workings of the innovation-KM "black box" are shifting from singularity toward complementarity in theorizing through embracing complexity theory; and moving beyond reliance on deductive and inductive reasoning toward applying abductive reasoning as the logic of discovery.

Complexity theory - given its emphasis on dynamic, non-linear systems operating at the edge of chaos - provides an effective foundation for building and testing accurate theory that makes a better sense of reality (Woodside, 2014). In so saying, however, it does not mean that researchers need be non-discriminatory and use all relevant theories. Indeed, such an approach would be unrealistic and raise the issue of validity. Selection of complementary theories must be parsimonious to avoid overly complex explanations that say very little about very much. 
Furthermore, assuming that truth is what works at the time, researchers should not feel it necessary to adhere to any existing logic of discovery. According to Peirce (1955), "abduction” or "abductive reasoning” is a third mode of logic for finding new practical knowledge that complements the traditional modes of deduction and induction. Peirce (1955) defines abduction as the consideration of surprising observed facts, which existing theories do not adequately explain and which could be understood by a proposition (or hypothesis) that when tested accounts for other observed facts. By incorporating both a practical approach (emphasizing observed facts grounded in contextual conditions and filled with existing theoretical knowledge) and a scientific approach (developing and testing hypotheses), abduction as a logic of discovery is arguably more productive in generating new knowledge grounded in complexity theory, than its deductive and inductive counterparts (Svennevig, 2001). This quality is most particularly evident when defining all possible (theoreticallysound) configurations of the drivers of an innovation outcome.

\subsection{Bridging theory and practice with a multi-level practice-based perspective}

The complexity of innovation-KM systems, where a number of combinatorial factors at both the macro- and micro-levels are in play (Eisenhardt \& Martin, 2000), presents difficulties in drawing certain practice-applicable conclusions. Consequently, building a bridge between complexity theory and practice - or developing "theories-in-use” (Argyris \& Schon, 1974) - requires adoption of a multi-level perspective that takes into account multidimensional innovation-KM phenomena at different levels (organizations/groups/individuals) and that weaves macro- and micro-explanations into common patterns with coherent attributes.

The “practice-based view” (Crossan \& Apaydin, 2010) - a contextual, dynamic perspective which sees practices that support KM for innovation as not created through single 
isolated activities, but rather ensuing from practical constellations of various actors where resources/knowledge are integrated and managed activities occur - is a promising way of linking macro influences to their micro foundations. The adoption of a multi-level practicebased view adds significant value to innovation-KM research by providing managers with more practical tools for: identifying early in the innovation development process whether and under what conditions individual knowledge-related attributes will increase/decrease the organizational-level innovation outcome; and, revealing alternative ways for combining these attributes to induce successful innovation.

\section{3. $\quad$ Moving toward pragmatic mixed-methods techniques}

A naturalistic research design that uses pragmatism (a philosophical underpinning for mixed methods studies and abductive reasoning - Feilzer, 2011) as guiding principle in methodology selection, is necessary for properly understanding innovation-KM mechanisms. Pragmatism has at its core the concept of "equifinality” or the idea that "a system can reach the same final state from different initial conditions and by a variety of different paths” (Katz \& Kahn, 1978, p.30). It entails acknowledgement that any knowledge produced through research is relative and not absolute, and that causal relationships are difficult to identify and non-lasting (Feilzer, 2011).

Whilst the application of mixed methods to innovation-KM research is increasing, albeit slowly, notably most studies employ qualitative and quantitative methods in juxtaposition without incorporating pragmatism (Feilzer, 2011). A major dilemma with this approach is a lesser level of accuracy in findings. One possible solution to this dilemma is to incorporate experiments into mixed methods design; but the number of experiments required may make such an approach impossible to carry out in the real world. However, the use of asymmetric "set-theoretic" techniques such as fsQCA and ABM that follow algorithms and 
build on the foundation of complexity theory is a potentially more fruitful approach for creating non-experimental research designs that can unravel causal complexity and allow for follow-up experiments. These techniques combine within one analysis a qualitative reasoning (analyzing data by cases/contexts, not by variables) and quantitative testing (facilitating interpretation by reducing a full case description to the shortest possible causally relevant expression) (Ragin, 2008).

fsQCA models relations among variables/attributes and enables the examination of all logically possible combinations of causally relevant attributes relating to an outcome, with necessary and sufficient conditions being differentiated (Ragin, 2008). ABM enables the study of interactive behaviors of individual micro-level agents, subgroups of agents, and aggregated macro-level agents with different levels of rules coexisting in a single model, and translates behavioral patterns into "what-if” scenarios that can be replicated/manipulated to investigate contingent outcomes (Garcia, 2005). The major tenets of these techniques are suitable for developing deep, accurate, mechanismic explanation of phenomena characterized by complex, inter-linked questions.

In essence, the benefits of fsQCA/ABM to innovation-KM research are two-fold. First, by endorsing the causal asymmetry assumption, the results match well with reality. Second, both techniques account for equifinality, the notion that multiple causal paths can lead to the same outcome. The application of such techniques offers: researchers the potential for richer and more accurate insights into innovation-KM; and practitioners the potential of alternative ways for successfully managing knowledge-related factors for innovation.

\section{Conclusion}

This study discusses the redirection of innovation-KM research toward transformative innovation, and advocates that future research should: embrace complexity theory and 
abductive reasoning as a basis for theorizing; bridge theory and practice through adoption of a multi-level perspective; and employ pragmatic mixed-methods techniques. Such an agenda offers great potential for the development of theories-in-use. 


\section{References}

Argyris,C.,\&Schon,D.A.(1974).Theories in practice.San Francisco,CA:Jossey-Bass.

Amstrong,J.C.(2012).Illusions in regression analysis.International Journal of Forecasting, 28(3),689-694.

Burnes,B.(2005).Complexity theories and organizational change.International Journal of Management Reviews,7(2),73-90.

Carlile,P.R.(2002).A pragmatic view of knowledge and boundaries: boundary objects in new product development.Organization Science,13(4),442-455.

Choi,B.,Poon,S.K.,\&Davis,J.G.(2008).Effects of knowledge management strategy on organizational performance: A complementarity theory-based approach.OmegaInternational Journal of Management Science,36(2), 235-251.

Cohen,W.M.,\&Levinthal,D.A.(1990).Absorptive capacity: A new perspective on learning and innovation.Administrative Science Quarterly,35(1),128-152.

Crossan,M.M.,\&Apaydin,M.(2010).A multi-dimensional framework of organisational innovation: a systematic review of the literature.Journal of Management Studies, 47(6),1154-1191.

Eisenhardt,K.M.,\&Martin,J.A.(2000).Dynamic capabilities: what are they?. Strategic Management Journal,21(10-11),1105-1121.

Feilzer,M.Y.(2010).Doing mixed methods research pragmatically: Implications for the rediscovery of pragmatism as a research paradigm.Journal of Mixed Methods Research,4(1),6-16.

Ganter,A.,\&Hecker,A.(2014).Configurational paths to organizational innovation: Qualitative comparative analyses of antecedents and contingencies.Journal of Business Research,67(6),1285-1292. 
Garcia,R.(2005).Uses of agent-based modeling in innovation/new product development research. Journal of Product Innovation Management,22(5),380-398.

Gopalakrishnan,S.,\&Damanpour,F.(1994).Patterns of generation and adoption of innovation in organizations: Contingency models of innovation attributes.Journal of Engineering and Technology Management,11(2):95-116.

Grant,R.M.(1996).Toward a knowledge-based theory of the firm.Strategic Management Journal,17,109-122.

Hansen,M.,Nohria,N.,\&Tierney,T.(1999).What’s your strategy for managing knowledge?. Harvard Business Review,77(2),106-116.

Johnson,G.,Melin,L.,\&Whittington,R.(2003).Micro strategy and strategizing: Towards an activity-based view. Journal of Management Studies,40:1-22.

Katz, D.,\&Kahn, R.L.(1978).The social psychology of organizations ( $2^{\text {nd }}$ edition).New York:Wiley.

Lane,P.J.,\&Lubatkin,M.(1998).Relative absorptive capacity and interorganizational learning.Strategic Management Journal,19(5),461-477.

Leischnig,A.,Geigenmueller,A.,\&Lohmann,S.(2014). On the role of alliance management capacity, organizational compatibility, and interaction quality in interorganizational technology transfer.Journal of Business Research,67(6),1049-1057.

Levinthal,D.A.,\&March,J.G.(1993).The myopia of learning.Strategic Management Journal, 14(S2),95-112.

Nonaka,I.(1994).A dynamic theory of organizational knowledge creation.Organization Science,5(1),14-37.

Ordanini,A.,Parasuraman,A.P.,\&Rubera,G.(2014).When the receipt is more important than the ingredients: a qualitative comparative analysis (QCA) of service innovation configurations.Journal of Service Research,17(2),134-149. 
Patokorpi,E.,\&Ahvenainen,M.(2009).Developing an abduction-based method for futures research.Futures,41(3),126-139.

Peirce,C.S.(1955).Philosophical writings of Peirce.New York:Dover.

Podsakoff,P.M.,MacKenzie,S.B.,Bacharach,D.G.,\&Podsakoff, N.P.(2005).The influence of management journals in the 1980s and 1990s.Strategic Management Journal, 26(5):473-488.

Ragin,C.C.(2008).Redesigning social inquiry: Fuzzy sets and beyond.Chicago:University of Chicago Press.

Siggelkow,N.,\&Rivkin,J.(2006).When exploration backfires: unintended consequences of multilevel organizational search. Academy of Management Journal,49(4),779-795.

Subramaniam,M.,\&Youndt,M.A.(2005).The influence of intellectual capital on the types of innovative capabilities.Academy of Management Journal,48(3),450-463.

Svennevig,J.(2001).Abduction as a methodological approach to the study of spoken interaction.Norskrift,103,1-22.

Szulanski,G.(1996).Exploring internal stickiness: impediments to the transfer of best practice within the firm.Strategic Management Journal,17(S2),27-43.

Teece,D.(1998).Capturing value from knowledge assets: the new economy markets for knowhow, and intangible assets.California Management Review,40(3),55-79.

Uhl-Bien,M.,Marion,R.,\&McKelvey,B.(2007).Complexity leadership theory: shifting leadership from the industrial age to the knowledge era.Leadership Quarterly, 18(4),298-318.

Woodside,A.G.(2013).Moving beyond multiple regression analysis to algorithms: Calling for adoption of a paradigm shift from symmetric to asymmetric thinking in data analysis and crafting theory.Journal of Business Research,66(4),463-472. 
Woodside,A.G.(2014).Embrace•perform•model: Complexity theory, contrarian case analysis, and multiple realities.Journal of Business Research,67(12),2495-2503

Zahra,S.A.,\&George,G.(2002).Absorptive capacity: A review, reconceptualization, and extension.Academy of Management Review,27(2),185-203. 
Table 1. "Highest-cited” versus "transformative” articles

\begin{tabular}{|c|c|}
\hline Highest-cited articles & Transformative articles \\
\hline \multicolumn{2}{|c|}{ Highest-cited transformative articles* } \\
\hline \multicolumn{2}{|c|}{ Nonaka 1994 [156] } \\
\hline \multicolumn{2}{|c|}{ Grant 1996 [155] } \\
\hline \multicolumn{2}{|c|}{ Eisenhardt \& Martin 2000 [153] } \\
\hline \multicolumn{2}{|c|}{ Zahara \& George 2002 [115] } \\
\hline \multicolumn{2}{|c|}{ Carlile 2002 [45] } \\
\hline Highest-cited incremental articles* & Non-highest-cited transformative articles \\
\hline Cohen \& Levinthal 1990 [217] & Choi, Poon \& Davis 2008 \\
\hline Lane \& Lubatkin 1998 [70] & Uhl-Bien, Marion \& McKelvey 2007 \\
\hline Levinthal \& March 1993 [72] & Garcia 2005 \\
\hline Szulanski 1996 [106] & Siggelkow \& Rivkin 2006 \\
\hline Teece 1998 [41] & Ganter \& Hecker 2014 \\
\hline Hansen, Nohria \& Tierney 1999 [52] & Leischnig, Geigenmueller \& Lohmann 2014 \\
\hline Subramaniam \& Youndt 2005 [42] & Ordanini, Parasuraman \& Rubera 2014 \\
\hline
\end{tabular}

*Citations-per-year are in parentheses. 